\title{
Space capsule probed for asteroid dust
}

\author{
Hayabusa holds lessons for future sample-return missions.
}

Tempering curiosity with caution, Japanese planetary scientists and their US colleagues are carefully preparing to open the recovery capsule from the Hayabusa spacecraft, which returned to Earth on 13 June following a spectacular high-speed re-entry over the Australian outback. If they're lucky, they may find a speck or two of material from asteroid 25143 Itokawa that could hold clues to the early days of the Solar System. But even if Hayabusa has returned empty, it will have given a boost to future asteroid missions.

Last week, the outer chamber of the 40 -centimetre-diameter aluminium capsule revealed traces of a gas that researchers say could have come from the 535-metre-long near-Earth asteroid on which Hayabusa twice touched down in November 2005. Yet the gas may simply be a bit of Earth's own atmosphere that sneaked in after the capsule landed - or it may have been emitted by the spacecraft itself.

$\mathrm{X}$-rays of the inner compartment, which is still tightly closed, have shown that it hides no grains larger than 1 millimetre. This is not entirely surprising. A proof-of-concept mission, Hayabusa was designed to fire a metal

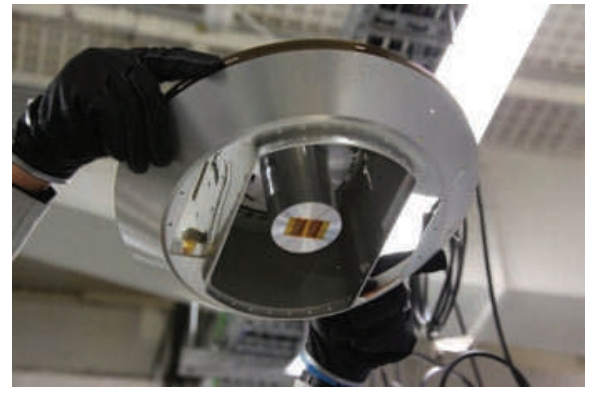

Empty or not, Hayabusa has whetted scientists' appetites for more sorties to near-Earth asteroids.

projectile at the asteroid's surface to kick up fragments of rock and dust for the sampleretrieval apparatus to capture. Technical glitches prevented the projectile from firing, leaving mission scientists to hope that some asteroid dust might still have found its way into Hayabusa. "Even a small grain would provide a lot," says Paul Abell, a planetary scientist at NASA's Johnson Space Center in Houston, Texas, who collaborated on the mission.

In fact, Hayabusa has already paid dividends, Abell says. When the craft reached Itokawa, it found, rather than a coherent, solid body, a boulder-strewn 'rubble pile.' "It was one of the most heavily studied asteroids, and yet when we got there, we were very surprised," says Abell.

The mission has also inspired future efforts. "They have clearly shown us the path forward to the inevitable large-scale exploration of the near-Earth asteroid population," says Dante Lauretta, a researcher at the University of Arizona's Lunar and Planetary Laboratory in Tucson.

Japan's Aerospace Exploration Agency (JAXA) is already planning a successor mission - Hayabusa-2 - to 1999 JU3, a carbonrich asteroid whose composition is expected to match the primitive Solar System more closely than does Itokawa's. It may also contain organic molecules that could shed light on the origins of life on Earth. Because the asteroid is an order of magnitude more massive than Itokawa, with a stronger gravitational pull, the craft will need more powerful versions of the ion thrusters with which Hayabusa manoeuvred around Itokawa.

Design and planning for Hayabusa-2 are essentially complete, says JAXA's Hajime Yano, who will coordinate the scientific planning. But

\section{Strikes could 'break' Italy's universities}

Science teaching in Italian universities could be crippled if tens of thousands of junior staff make good on threats to strike later this year. The 'ricercatori' (researchers) are protesting harsh university budget cuts and a looming reform bill, which threaten their futures.

The bill was designed to align Italy's struggling university system with international norms by, among other measures, eliminating the ricercatore position and introducing instead a tenure-track system. It is broadly welcomed in university circles, but massive funding cuts may make its goals unachievable.

Ricercatori - the lowest academic grade, beneath 'associate professor' and 'full professor' - currently move up the academic scale by applying for open positions in competitions organized by the government. The proposed tenure-track system would instead offer young scientists three-year contracts that could be renewed once. If a central panel of experts then judged them suitable for tenure, they would be placed on a 'habilitation' list; universities would consider listed academics for

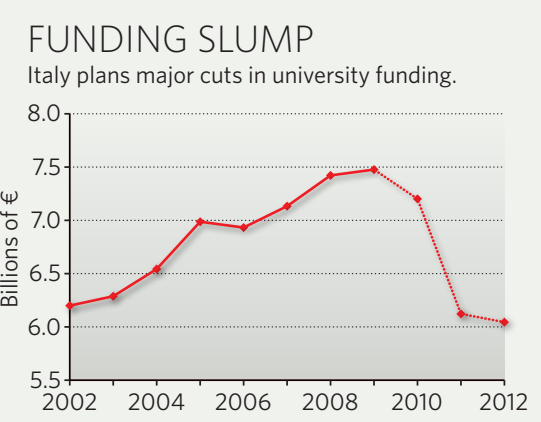

professorships. But the law does not offer a way for existing ricercatori to get on the list. "We are afraid we will be stuck as ricercatori for the rest of our lives," says neuropsychologist Alessia Tessari, a researcher at the University of Bologna.

A survey conducted at the University of Turin suggests that two-thirds of Italy's 25,000 ricercatori will stop teaching courses and running exams during the strike. A walkout on this scale "will break the university system", says chemist Dario Braga, pro-rector for research at the
University of Bologna. Ricercatori are not obliged to teach, but in practice they run a significant proportion of courses, particularly in the sciences.

Enrico Decleva, rector of the University of Milan and head of the Conference of Italian University Rectors, admits that the strike would be crippling. "But we also have a much bigger problem," he says. "The huge budget cuts will hit the universities at every level."

Tessari says that she and many other ricercatori plan to strike as much to protest the budget threat as to protect their positions. Last year, the government decided to slash the already tight university budget from $€ 7.49$ billion (US\$9.27 billion) to $€ 6.05$ billion between 2009 and 2012 , a fall of $19 \%$. In addition, an emergency financial budget now under discussion in parliament, which is intended to save about $€ 24$ billion in public spending by 2012 , would allow universities to fill just one post for every five vacated over the next three years and one for every two in 2014, almost wiping out recruitment.

Most agree that Italy's universities are badly in need of reform. But the cuts may make it 
funding remains an obstacle. For the current fiscal year, the project received only $¥ 30$ million (US $\$ 335,000$ ) of its requested $¥ 1.7$ billion. But on 15 June, amid excitement at the successful re-entry of the Hayabusa recovery capsule, Japan's science and technology minister promised to increase the budget. Yano hopes for a 2014 launch, which would require the estimated $¥ 25$-billion budget to be allocated by next April. On that schedule, samples from 1999 JU3 could be in scientists' hands by 2020 .

Interest in asteroid missions has also been on the rise in the United States. In June, US President Barack Obama called for a manned trip to an asteroid. And late last year, the OSIRIS-REx project, also a sample-return mission targeting a carbon-rich asteroid, was selected as a finalist in NASA's New Frontiers Program, which would provide US\$650 million. Deputy principal investigator Lauretta hopes for a 2016 launch, a rendezvous with asteroid 1999 RQ36 in November 2019, and samples returned by September 2023.

Lauretta says the OSIRIS-REx team has studied the Hayabusa mission "in excruciating detail" and will extend operations at the asteroid to some 15 months compared with Hayabusa's 6 weeks. Hayabusa's troubles, he says, taught a clear lesson: "Take the time to thoroughly study the asteroid and safely design the sampling manoeuvre." David Cyranoski

impossible to raise standards and increase universities' autonomy, two goals of the reform bill. A net of complex rules, some of which are in a constant and paralysing state of flux, stymies the universities. Academic recruitment and promotion - a mostly centralized procedure had in any case almost ground to a halt for five years before a trickle of new posts were opened this year, because controversial selection rules were being revised. Powerless to hire, universities will not be able to take advantage of the reforms.

The reform bill is scheduled to be approved before August, but that date is likely to slip. In the meantime, academics are lobbying for compromises. Decleva says, for example, that the government must ensure that researcher-grade scientists can compete with new tenure-trackers for promotion to associate professors.

If these changes don't happen, and the ricercatori carry out their threat to strike, universities may find themselves unable to open for teaching in September. The number of courses in Italian universities rose from 116,000 in 2001-02 to 172,000 in 2007-08, and without the army of ricercatori there will not be enough professors able to take over, says Decleva. Alison Abbott

\section{Stem-cell furore erupts}

Long-rumbling hostilities between stemcell researchers in Germany exploded into a blazing public row last week, after Nature published a critical reanalysis of data from a high-profile 2008 article.

The researchers behind the original work $^{1}$, led by Thomas Skutella of the University of Tübingen, reported using cells from adult human testes to create pluripotent stem cells with similar properties to embryonic stem cells.

Unlike other adult cells, these reproductive or 'germline' stem cells can be reprogrammed for pluripotency without the need to introduce additional genes, a step that often relies on a virus. That could make them safer for future use in medicine.

The paper made headlines because such pluripotent stem cells might be used instead of ethically sensitive human embryonic tissue. Soon after its publication, however, some stem-cell scientists said that the evidence for pluripotency was unconvincing. They also complained that Skutella would not distribute cells to other labs for verification, even though Nature requires its authors to share all published research resources.

Hans Schöler, a director at the Max Planck Institute for Molecular Biomedicine in Münster and an author of last week's critical comment ${ }^{2}$, says that he proclaimed Skutella's achievement as a breakthrough when he first saw the data at a meeting, but became doubtful after seeing the published paper. "If this paper is wrong, then a lot of scientists are wasting time, energy and money in trying to follow up on it," he says. Others fear that the episode is undermining the credibility of the field.

In response, Skutella last week asked the DFG, Germany's main research-funding agency, to conduct an investigation both of his paper in Nature and of what he claims is a witch-hunt against him. Schöler, who also works with germline stem cells, says that he would welcome such a move.

Pluripotent cells should form teratomas - encapsulated tumours comprising different cell types - when injected under the skin of mice, and also exhibit a particular profile of gene expression.
"The teratoma pictures in the Nature paper were not terribly convincing but that didn't concern me too much at first," says Schöler. "It was the failure to provide cells that started to concern me." After more than a year of requests for access, he decided to reanalyse data in the paper in Nature showing which genes in the disputed cells were being expressed.

Together with bioinformaticians, he compared the genes' expression profile with those of other cells in public databases and found that it overlapped with a type of connective-tissue cell called fibroblasts but not with pluripotent stem cells. Schöler suggests that fibroblasts may have contaminated Skutella's samples. But Skutella and his colleagues deny ${ }^{3}$ mistaking fibroblasts for pluripotent cells. Skutella says that comparison of gene-expression data is meaningless "if the cells being compared were not processed identically".

Takashi Shinohara at Kyoto University in Japan, whose team in 2004 generated the first pluripotent germline stem cells from mice, shares Schöler's concerns about the expression data. He says that fibroblasts and pluripotent cells have different geneexpression profiles even if the cells are not processed in similar ways, and adds that it would be helpful to see Skutella's cells.

In a corrigendum to his original paper in August 2009, Skutella and his co-authors said that they wanted to share the cells but that the original agreement signed by tissue donors precluded distribution to third parties. Having gained broader consent from some donors, Skutella now promises to distribute the cells once they have been quality-checked. But stem-cell researcher Rudolf Jaenisch at the Whitehead Institute for Biomedical Research in Cambridge, Massachusetts, is not impressed: "It's a big problem not providing the cells for what is nearly two years - whatever the excuses, this is bad."

Ulrike Beisiegel, ombudsman for the DFG, says her office will decide "soon" whether to take up the investigations. Alison Abbott
1. Conrad, S. et al. Nature $456,344-349$ (2008)
2. Ko, K. et al. Nature doi:10.1038/nature09089 (2010). 